\title{
Reference Values for the 6-min Walk Distance in Healthy Children Age 7 to 12 Years in Brazil: Main Results of the TC6minBrasil Multi-Center Study
}

\author{
Lucas de Assis Pereira Cacau PT PhD, Vitor Oliveira Carvalho PT PhD, \\ Alessandro dos Santos Pin PT PhD, Carlos Raphael Araujo Daniel PhD, \\ Daisy Satomi Ykeda PT PhD, Eliane Maria de Carvalho PT PhD, \\ Juliana Valente Francica PT PhD, Luíza Martins Faria PT PhD, Mansueto Gomes-Neto PT PhD, \\ Marcelo Fernandes PT PhD, Marcelo Velloso PT PhD, Marlus Karsten PT PhD, \\ Patrícia de Sá Barros PT PhD, and Valter Joviniano de Santana-Filho PT PhD; \\ on behalf of the TC6minBrasil Investigators
}

\begin{abstract}
INTRODUCTION: Brazil is a country with great climatic, socioeconomic, and cultural differences that does not yet have a reference value for the 6-min walk test (6MWT) in healthy children. To avoid misinterpretation, the use of equations to predict the maximum walk distance should be established in each country. OBJECTIVES: We sought to establish reference values and to develop an equation to predict the 6-min walk distance for healthy children in Brazil. METHODS: This is a cross-sectional multi-center study that included 1,496 healthy children, aged 7 to $12 \mathrm{y}$, assessed across 11 research sites in all regions of Brazil, and recruited from public and private schools in their respective regions. Each child was assessed for weight and height. Walk distance was our main outcome. An open-source software environment for statistical computing was used for statistical analysis. RESULTS: We observed a higher average distance walked by boys $(531.1 \mathrm{~m})$ than by girls $(506.2 \mathrm{~m})$, with a difference of $24.9 \mathrm{~m}(P<.001)$. We established 6MWT reference values for boys with the following equation: Distance $=(16.86 \times$ age $)+(1.89 \times \Delta$ heart rate $)-$ $(0.80 \times$ weight $)+(336.91 \times \mathbf{R} 1)+(360.91 \times \mathbf{R} 2)$. For girls the equation is as follows: Distance $=(13.54 \times$ age $)+(1.62 \times \Delta$ heart rate $)-(1.28 \times$ weight $)+(352.33 \times \mathbf{R} 1)+(394.81 \times \mathbf{R} 2)$. CONCLUSION: Reference values were established for the 6MWT in healthy children aged 7-12 y in Brazil. Key words: exercise test; child; pediatrics; reference values. [Respir Care 2018;63(3):339-346. (C) 2018 Daedalus Enterprises]
\end{abstract}

\section{Introduction}

The 6-min walk test (6MWT) is a well-established tool for assessing submaximal exercise capacity in people with

Messrs de Assis Pereira Cacau, Carvalho, and de Santana-Filho are affiliated with the Departamento de Fisioterapia e Pós-Graduaçáo em Ciências da Saúde da Universidade Federal de Sergipe, Aracaju, Brazil, as well as The GREAT Group (Grupo de Estudos em Atividade Física), Brazil. Messrs Fernandes and Gomes-Neto are also affiliated with The GREAT Group. Mr dos Santos Pin is affiliated with the Departamento de Fisioterapia da Universidade Federal do Amazonas, Coari, Brazil. Mr Araujo Daniel is affiliated with the Departamento de Estatística e Ciências Atuariais da Universidade Federal de Sergipe, Aracaju, Brazil. Ms cardiopulmonary diseases worldwide. ${ }^{1}$ In the 6MWT, patients are instructed to walk as far as they can for $6 \mathrm{~min}$ in a straight, flat, $30-\mathrm{m}$ corridor. $^{2}$ This test is easy to perform, 
has low cost, and is well accepted in clinical practice and research. ${ }^{1,2}$ The $6 \mathrm{MWT}$ is largely used for the assessment of exercise capacity before and after an intervention, such as an exercise training program, or for the prognostic stratification of selected patients, such as those with heart failure or COPD. ${ }^{2-4}$

Although the 6MWT has been widely performed in adults, its use in children has increased in the last 10 years. ${ }^{5}$ The $6 \mathrm{MWT}$ is safe, well understood, and well tolerated in healthy children and in those with various diseases, such as cardiorespiratory $6,7,8$ or neuromuscular disorders. ${ }^{9,10}$

Due to the high relevance of the 6MWT, some countries have already established reference values for the maximum walk distance for healthy children, such as China, ${ }^{11}$ United Kingdom, ${ }^{12}$ Thailand, ${ }^{13}$ Turkey, ${ }^{14}$ India,,${ }^{15}$ and the United States of America. ${ }^{16}$ Despite this, Brazil, a country with large climatic, socioeconomic, and cultural differences, does not have representative reference values for healthy children. ${ }^{17}$ It is known that the use of formulas to predict the maximum walk distance in the 6MWT estab-

iated with the Departamento de Fisioterapia da Universidade Federal de Minas Gerais, Belo Horizonte, Brazil. Mr Karsten is affiliated with the Departamento de Fisioterapia da Universidade Federal do Rio Grande do Sul, Porto Alegre, Brazil. Ms de Sá Barros is affiliated with the Departamento de Fisioterapia da Universidade Federal de Goiás, Jataí, Brazil.

Authors of the TC6minBrasil study: Steering Committee: Vitor Oliveira Carvalho PT PhD (chief investigator), Marcelo Fernandes PT PhD (cochief investigator), Lucas de Assis Pereira Cacau PT PhD (research coordinator), Carlos Raphael Araújo Daniel PhD (statistician). Study design committee: Vitor Oliveira Carvalho PT PhD; Marcelo Fernandes PT PhD; Marcelo Biscegli Jatene MD PhD; Karen Moraes PT; Roberta Lima PT. Investigator Sites: Federal University of Amazonas - UFAM, Coari, Amazonas (Alessandro dos Santos Pin PT PhD); State University of Piaui - UEPI, Teresina, Piaui (Daisy Satomi Ykeda PT PhD); Federal University of Uberlândia - UFU, Uberlândia, Minas Gerais (Eliane Maria de Carvalho PT PhD); São Judas University - São Paulo (Juliana Valente Francica PT PhD); Centro Universitário Estácio de Santa Catarina - São José - Florianópolis (Luíza Martins Faria PT MSc); Federal University of Bahia - UFBa, Salvador (Mansueto Gomes-Neto PT PhD and Micheli Bernardone Saquetto PT PhD); Federal University of Minas Gerais UFMG, Belo Horizonte (Marcelo Velloso PT PhD and Laura Cabral Alves PT PhD); Federal University of Rio Grande do Sul - UFRS - Porto Alegre (Marlus Karsten PT PhD); Universidade Presbiteriana Mackenzie, São Paulo (Marcelo Fernandes); Tiradentes University - UNIT Aracaju (Lucas de Assis Pereira Cacau). Writing committee: Vitor Oliveira Carvalho PT PhD; Lucas de Assis Pereira Cacau PT PhD; Marcelo Fernandes PT Carlos Raphael Araujo Daniel PhD; Valter Joviniano de SantanaFilho PT PhD.

Correspondence: Lucas de Assis Pereira Cacau PT PhD, Programa de pós-graduação em Ciencias da Saúde da Universidade Federal de Sergipe (UFS), Rua Claúdio Batista, s/n Santo Antonio, Aracaju, SE, Brazil, 49060-100. E-mail: lucas.cacau@yahoo.com.br

DOI: $10.4187 /$ respcare. 05686

\section{QUICK LOOK}

\section{Current knowledge}

Several countries around the world have already established reference values for the 6-min walk test in healthy children. This concern about local reference values can minimize the test's interpretation errors. However, these Brazilian reference values were not available.

\section{What this paper contributes to our knowledge}

This study established reference values for the 6-min walk test in healthy children in Brazil at 7-12 y old. Now, researchers and clinicians have local reference values to make a more precise interpretation of the test. The work is relevant because it is a multi-center study that considered all regions of Brazil through a representative sample.

lished in other countries may lead to significant interpretation error.

The aim of this study was to establish reference values and to elaborate an equation to predict the 6-min walk distance (6MWD) in healthy children in Brazil. In addition, our study aimed to test the equation in an independent sample.

\section{Methods}

\section{Study Design and Population}

This was a cross-sectional multi-center study that included healthy children between 7 and 12 y old from all Brazilian regions from August 2013 to December 2016. Children with some type of indisposition on the day of the test (eg, a cold or fever) or those did not understand the instructions or performed the 6MWT in disagreement with international standards ${ }^{1}$ were excluded. The judgment of the efficiency of the test was at the discretion of each investigator. The eligibility criteria for the research sites (Brazilian physiotherapy schools) in the TC6minBrasil study were to have a physical structure and human resources according to the American Thoracic Society ${ }^{1}$ (ATS) guideline for the 6MWT, such as a flat and straight corridor that is $30 \mathrm{~m}$ long, a pulse oximeter, a scale, a tape measure, a sphygmomanometer, a stethoscope, a stopwatch (or another means to track time, such as a watch or a mobile telephone). After this stage, the research steering committee sent a letter of invitation to the coordinator of research responsible for the research sites. After acceptance, the research sites were instructed how to perform the 6MWT accord- 
ing to the international recommendations. ${ }^{1}$ The training was carried out through tutorial videos, conferences, telephone contacts, and printed material that covered all the phases of the research. The research sites had open communication channels with the TC6minBrasil study committee through videoconference, e-mail, or telephone.

All participants and legal guardians involved in the study were informed about the research aims and procedures. A legal representative signed the free and informed consent form approved by an ethics committee (CAAE 08827713.1.1001.0065) before participating in the study. This study was supported by Fapitec-SE (MS/CNPq/FAPITEC/SE/SES - PPSUS, No. 02/2013).

\section{Sample Size Calculation}

The sample size was calculated considering the construction of a $95 \%$ reference curve for the 6MWD by healthy children in Brazil aged between 7 and $12 \mathrm{y}$, assuming the normal distribution for the distance covered. We considered in the sample size calculation the 12 subpopulations formed by the 6 age classes, that is, 7-12 y, and by sex. The estimated number of children in each sub-population of interest was 114 when we assumed an absolute error of $1.5 \%$ in relation to the percentiles of $2.5 \%$ and $97.5 \%$. In the end, 1,496 children were selected from all Brazilian regions by stratified sampling by age and sex. The distribution of the sample in the different regions took into account the population density, seeking the representativeness according to IBGE data of 2010. In this distribution, the population of the North was $8.3 \%$, the Northeast was $27.8 \%$, the Southeast was $42.1 \%$, the South was $14.4 \%$, and the CenterWest was $7.4 \%$, totaling $100 \%$ of the Brazilian population. ${ }^{18}$

Considering the sample size calculation, it was proposed that 1 research site in the North would assess 118 children, 3 research sites in the Northeast would assess a total of 415 children ( 2 research sites with 138 and 2 research sites with 139), 1 research site in the CentralWest region would assess 112 children, 4 research sites in the Southeast region would assess a total of 627 children ( 3 research sites with 157 and 1 research site with 156), and 2 research sites in the South region would assess a total of 224 children (112 per research site), totaling 1,496 children in Brazil. It was recommended that each research site distribute the number of participants equally, by sex, in the 6 age groups.

\section{Training of Research Sites}

After the formal acceptance of each eligible research site to participate in the TC6minBrasil study, a video-

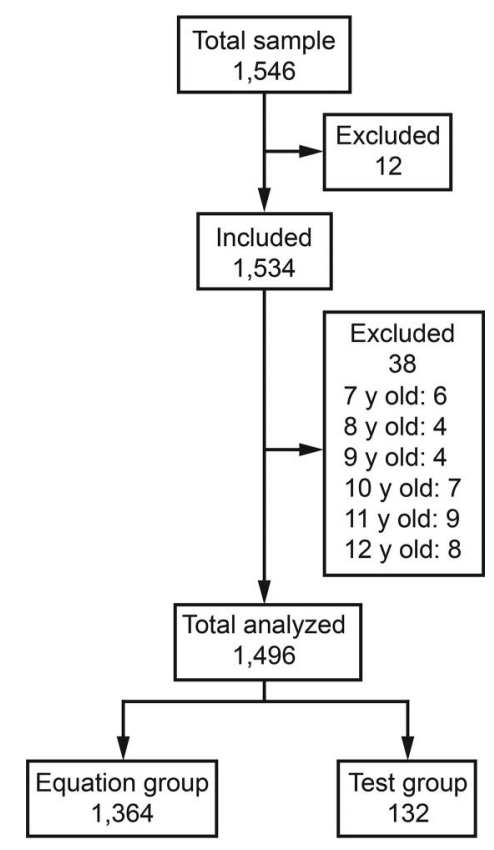

Fig. 1. Flowchart.

conference was held for a formal presentation. In this first conference, the study design was carefully explained. Moreover, standardized instructions were given regarding the organization of the physical space and application of the test according to the ATS guideline. ${ }^{1}$ These instructions were given via tutorial videos, videoconference calls, and a checklist of the materials necessary to carry out the tests and data collection. After the assembly of the 6MWT circuit, the steering committee contacted the research sites by telephone to answer any queries.

After each research site completed the assessment of the first 10 children, there was another videoconference to check whether the test and data collection were being performed properly. Thenceforth telephone calls to the research site were made after the evaluation of every 50 children. A final videoconference was held at the end of the study to audit the data.

\section{Screening of Participants by Research Sites}

The research sites were responsible for recruiting the participants. To carry out the screening, a standardized form about the child's current health condition was sent to parents or any legal authority. An Internet address was also provided with an example of the 6MWT to allow parents or guardians to see the procedures of the test. After the consent was signed and the health screening form was completed, the researchers responsible for each site sched- 
Table 1. Sample Characteristics by Age and Sex

\begin{tabular}{|c|c|c|c|c|c|c|}
\hline Age, y & Height, m & Weight, kg & $\Delta$ Heart Rate, beats/min & BMI, $\mathrm{kg} / \mathrm{m}^{2}$ & Final Borg & Resting $\mathrm{S}_{\mathrm{pO}_{2}}, \%$ \\
\hline \multicolumn{7}{|l|}{ Boys } \\
\hline $7, n=129$ & $1.26(0.06)$ & $26.55(5.32)$ & $20.21(20.73)$ & $16.52(2.32)$ & $2.0(3.0)$ & $97.20(2.04)$ \\
\hline $8, n=117$ & $1.32(0.07)$ & $30.89(6.95)$ & $21.66(20.96)$ & $17.72(3.08)$ & $2.5(3.0)$ & $97.61(1.52)$ \\
\hline $9, n=117$ & $1.36(0.06)$ & $32.66(5.82)$ & $20.66(19.81)$ & $17.48(2.48)$ & $2.0(2.5)$ & $97.03(3.63)$ \\
\hline $10, n=114$ & $1.42(0.07)$ & $35.42(9.09)$ & $30.44(24.96)$ & $17.48(3.15)$ & $2.0(3.5)$ & $97.68(1.86)$ \\
\hline $11, n=133$ & $1.48(0.08)$ & $40.89(10.54)$ & $26.51(31.26)$ & $18.54(3.50)$ & $2.0(3.0)$ & $97.56(1.63)$ \\
\hline $12, n=121$ & $1.53(0.09)$ & $45.33(10.38)$ & $27.52(26.10)$ & $19.15(3.42)$ & $2.0(3.75)$ & $97.49(2.51)$ \\
\hline Total, $n=731$ & $1.40(0.12)$ & $35.33(10.43)$ & $24.47(24.65)$ & $17.82(3.14)$ & $2.0(3)$ & $97.43(2.30)$ \\
\hline \multicolumn{7}{|l|}{ Girls } \\
\hline $7, n=118$ & $1.25(0.06)$ & $26.30(6.74)$ & $24.67(24.58)$ & $16.64(3.00)$ & $2.0(2.5)$ & $97.16(2.68)$ \\
\hline $8, n=122$ & $1.30(0.07)$ & $29.88(6.44)$ & $20.49(28.60)$ & $17.57(3.08)$ & $2.0(3)$ & $97.34(1.91)$ \\
\hline $9, n=130$ & $1.37(0.08)$ & $33.68(9.44)$ & $23.84(21.45)$ & $17.81(3.49)$ & $2.0(3)$ & $97.32(3.01)$ \\
\hline $10, n=141$ & $1.43(0.08)$ & $37.43(9.52)$ & $29.55(26.54)$ & $18.16(3.49)$ & $2.0(3)$ & $97.80(1.85)$ \\
\hline $11, n=126$ & $1.49(0.08)$ & $42.40(10.15)$ & $28.50(28.89)$ & $18.90(3.35)$ & $3.0(3.5)$ & $97.69(1.91)$ \\
\hline $12, n=130$ & $1.53(0.08)$ & $45.65(9.33)$ & $32.42(27.25)$ & $19.44(3.28)$ & $3.0(4)$ & $97.63(2.08)$ \\
\hline Total, $n=767$ & $1.40(0.12)$ & 36.09 (10.99) & $26.71(26.55)$ & $18.11(3.40)$ & $2.0(3.5)$ & $97.50(2.28)$ \\
\hline \multicolumn{7}{|c|}{$\begin{array}{l}\text { Values expressed as mean and standard deviation in parentheses. The median and interqua } \\
\text { parentheses and the interquartile amplitude is what is in parentheses. } \\
\Delta \text { Heart Rate = difference between the heart rate at the 6th minute and resting heart rate } \\
\mathrm{BMI}=\text { body mass index } \\
\text { Resting } \mathrm{S}_{\mathrm{pO}_{2}}(\%)=\text { oxygen saturation at rest }\end{array}$} \\
\hline
\end{tabular}

uled a date for each subject to come to the site for testing and data collection.

\section{MWT}

The main outcome of the 6MWT was the maximum walk distance. The research sites recruited children in public and private schools in their respective regions. Data were collected and inserted into standardized forms. Each child was initially assessed to obtain the values of weight and height. After initial data collection, the child remained resting in a chair near the start line of the test for at least $10 \mathrm{~min}$. During this time, the researchers recorded heart rate (beats/min), peripheral oxygen saturation (\%), and blood pressure (mm Hg).

The researchers explained to the test subject that the goal was to walk as far as possible for $6 \mathrm{~min}$ without running or jogging. After the explanation, the investigator demonstrated the test by performing a complete turn. After receiving the instructions, the child was allowed to start the test when he or she chose. Standardized incentive phrases were used according to ATS guidelines. ${ }^{1}$

At the sixth minute of the test, the investigator instructed the participant to stop. The investigator went to the child with a chair to sit down. At this time researchers recorded a rating of perceived exertion (modified Borg Scale), peripheral oxygen saturation, final heart rate, and the heart rate at the 1 and 2 min of recovery. The maximum 6MWD was measured.
Table 2. Maximum Walk Distance by Age and Sex

\begin{tabular}{lccl}
\hline \hline Age, y & $\begin{array}{c}\text { Distance in Meters for } \\
\text { Males, mean (SD) }\end{array}$ & $\begin{array}{c}\text { Distance in Meters for } \\
\text { Females, mean (SD) }\end{array}$ & $P$ \\
\hline 7 & $474.4(83.29)$ & $469.1(87.08)$ & .75 \\
8 & $514.1(77.13)$ & $485.5(91.30)$ & .007 \\
9 & $525.0(81.02)$ & $505.5(74.58)$ & .03 \\
10 & $549.5(87.24)$ & $517.5(89.61)$ & .008 \\
11 & $557.3(98.72)$ & $530.3(85.18)$ & .03 \\
12 & $568.0(99.74)$ & $524.5(102.50)$ & .002 \\
Total & $531.1(93.83)$ & $506.2(91.04)$ & $<.001$ \\
\multicolumn{4}{l}{} \\
Tukey test was used for comparison of the overall average. $P<.05$ was considered \\
statistically significant. \\
\hline
\end{tabular}

\section{Statistical Analysis}

The collected data were inserted in a standardized worksheet and sent to the steering committee by each research site. For data analysis, we used the statistical program R, v. 3.3.2. Initially, the correlation between all independent variables and also the dependent variable was verified with the Pearson coefficient (bivariate correlation). The hypothesis of equal means for the distance walked between different groups of qualitative variables such as sex and region were analyzed using the Tukey test. Then several models were adjusted by linear regression using sex, Brazilian region, age, height, body mass index (BMI), and change $(\Delta)$ in heart rate from the group of 1,364 subjects used to establish the equation. The equations were then 

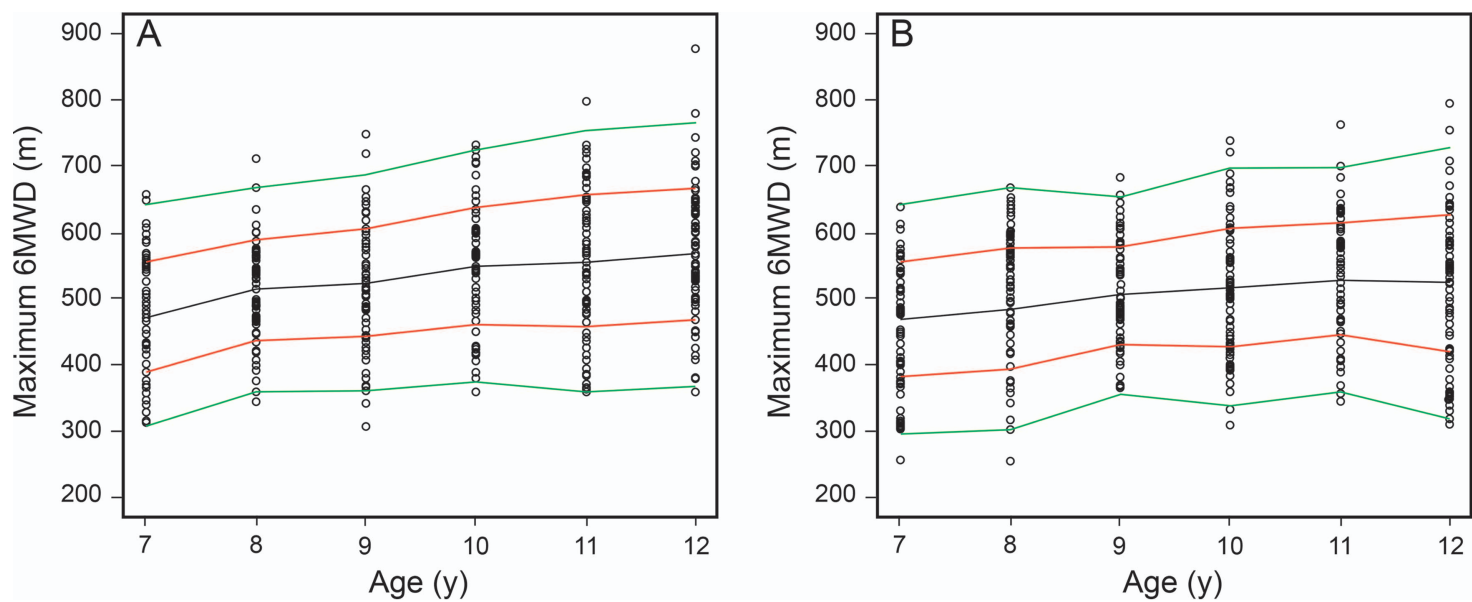

Fig. 2. Reference curve of maximum 6-min walk distance (6MWD) by age groups. Black lines represent the mean and red and green lines show $\pm 1 \mathrm{SD}$ and $\pm 2 \mathrm{SD}$, respectively. Reference values are between the mean and $-1 \mathrm{SD}$.

Table 3. Reference Values for the 6-min Walk Distance

\begin{tabular}{ccccc}
\hline \hline Age, $\mathrm{y}$ & Mean Distance, $\mathrm{m}$ & $-1 \mathrm{SD}$ & $-2 \mathrm{SD}$ & $-3 \mathrm{SD}$ \\
\hline Boys & & & & \\
7 & 474.4 & 391.1 & 307.8 & 224.6 \\
8 & 514.1 & 437.0 & 359.8 & 282.7 \\
9 & 525.0 & 444.0 & 363.0 & 282.0 \\
10 & 549.5 & 462.2 & 375.0 & 287.7 \\
11 & 557.3 & 458.6 & 359.9 & 261.1 \\
12 & 568.0 & 468.3 & 368.5 & 268.8 \\
Girls & & & & \\
7 & 469.1 & 382.1 & 295.0 & 207.9 \\
8 & 485.5 & 394.2 & 302.8 & 211.5 \\
9 & 505.5 & 430.9 & 356.3 & 281.8 \\
10 & 517.5 & 427.9 & 338.3 & 248.7 \\
11 & 530.3 & 445.2 & 360.0 & 274.8 \\
12 & 524.5 & 422.0 & 319.5 & 217.0 \\
& & & & \\
\hline$-n$ SD $=$ subtracting the average distance of $n$ SD & & \\
\hline
\end{tabular}

validated using the test group (132 independent healthy children). Then new models were adjusted for boys and girls. The best models were selected using the mean error, standard deviation of the errors of prediction, and Mean Squared Error (MSE), as well as by visual scatter plots.

\section{Results}

A total of 1,546 children were eligible for this study, and 1,496 were included in our final analysis; reasons for exclusion are shown in Figure 1. The sample was composed of children 7-12 y old and is characterized in Table 1. The results were similar between both boys and girls for all the independent variables, with height and weight increasing steadily, as expected, from approximately $1.25 \mathrm{~m}$ and $26 \mathrm{~kg}$ at $7 \mathrm{y}$ to $1.53 \mathrm{~m}$ and $36 \mathrm{~kg}$ at
Table 4. Regional Differences of the 6-min Walk Distance

\begin{tabular}{lrrrc}
\hline \hline \multicolumn{1}{c}{ Region } & Difference & $\begin{array}{r}\text { Lower } \\
\text { Limit }\end{array}$ & $\begin{array}{c}\text { Upper } \\
\text { Limit }\end{array}$ & $P$ \\
\hline South and North & 123.48 & 94.93 & 152.04 & $<.001$ \\
Center-West and North & 92.25 & 59.09 & 125.41 & $<.001$ \\
Southeast and North & 79.85 & 55.05 & 104.65 & $<.001$ \\
South and Northeast & 64.24 & 43.01 & 85.46 & $<.001$ \\
Northeast and North & 59.25 & 33.52 & 84.97 & $<.001$ \\
South and Southeast & 43.63 & 23.54 & 63.73 & $<.001$ \\
Center-West and Northeast & 33.00 & 5.90 & 60.10 & .01 \\
South and Midwest & 31.23 & 1.43 & 61.03 & .03 \\
Southeast and Northeast & 20.60 & 4.79 & 36.41 & .001 \\
Center-West and Southeast & 12.40 & -13.82 & 38.62 & .70 \\
Region 1 and Region 2 & 45.03 & 35.08 & 54.98 & $<.001$ \\
& & & & \\
\hline Mean values expressed in meters. Tukey test was used for comparison between regions. \\
$P$ values was considered statistically significant. & & & \\
Region 1 = South, Southeast, and Midwest & & & & \\
Region 2 $=$ North and Northeast & & & & \\
\hline
\end{tabular}

12 y, respectively. Researchers also observed higher BMI with age, but $\Delta$ heart rate, final Borg rating, and resting $\mathrm{S}_{\mathrm{pO}_{2}}$ did not present any ascending or descending pattern associated with age. Regarding the main outcome of this study (6MWD), there was a significant difference between boys and girls, with boys walking longer distances for all ages except $7 \mathrm{y}$, the only group whose difference was not statistically significant. When comparing the maximum 6MWD between boys and girls, we identified a mean difference of $24.9 \mathrm{~m}(P<.001)$ in favor of boys (Table 2). The overall average was $518.4 \pm 93.2 \mathrm{~m}$. When comparing the maximum 6MWD between the sexes, we identified a mean difference of $24.9 \mathrm{~m}(P<.001)$ in favor of boys. We also identified the variability in relation to age (Table 2 ). 

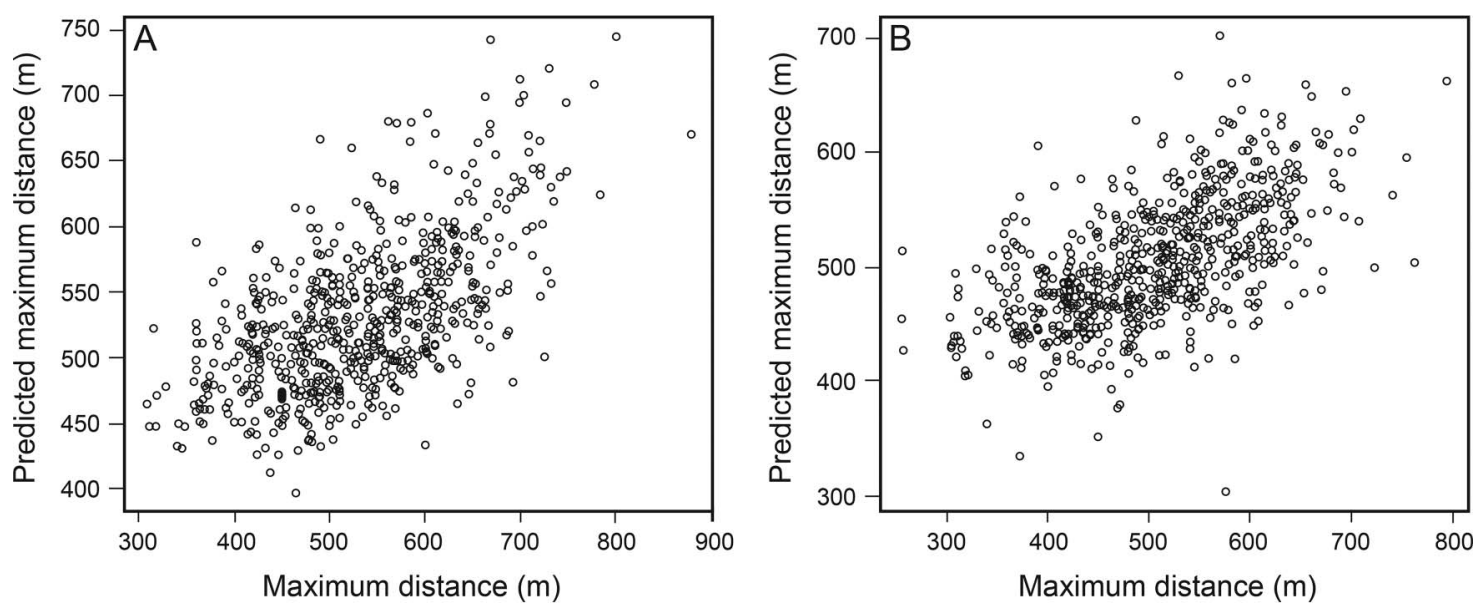

Fig. 3. Correlation between predicted and walked distance for the 1,364 children (equation group). Pearson correlation. $A$ : $R=0.61$ and $P<.001$ for boys. B: $\mathrm{R}=0.60$ and $P<.001$ for girls.

The reference values for the maximum 6MWD were obtained by subtracting the standard deviations of each age group from the corresponding mean 6MWD for boys: $391-474 \mathrm{~m}$ for $7 \mathrm{y}, 437-514 \mathrm{~m}$ for $8 \mathrm{y}, 444-525 \mathrm{~m}$ for $9 \mathrm{y}$, $462-549 \mathrm{~m}$ for $10 \mathrm{y}, 458-557 \mathrm{~m}$ for $11 \mathrm{y}$, and $468-568 \mathrm{~m}$ for $12 \mathrm{y}$; and then doing the same for girls: $382-469 \mathrm{~m}$ for $7 \mathrm{y}, 394-485 \mathrm{~m}$ for $8 \mathrm{y}, 430-505 \mathrm{~m}$ for $9 \mathrm{y}, 427-517 \mathrm{~m}$ for $10 \mathrm{y}, 445-530 \mathrm{~m}$ for $11 \mathrm{y}$, and $422-504 \mathrm{~m}$ for $12 \mathrm{y}$ (Figure 2). After establishing the normal range, 2 reference curves (boys and girls) were created for the maximum 6MWD by age group from 7 to $12 \mathrm{y}$ (Table 3 ).

The maximum 6MWD was compared among the 5 regions of Brazil (North, Northeast, South, Southeast, and Center-West), and a significant difference was found. Therefore, we decided to take into account the region of Brazil in establishing the formula to predict the maximum 6MWD. To avoid the use of a coefficient for each region, the research sites were grouped into 2 large regions: North/Northeast (R1) and South/Southeast/Center-West (R2) (Table 4).

After the investigation of the correlation matrix, the variables considered to be potentially associated with the 6MWD were age $(\mathrm{y})$, weight $(\mathrm{kg})$, height $(\mathrm{m})$, BMI $\left(\mathrm{kg} / \mathrm{m}^{2}\right)$, sex, and $\Delta$ heart rate (beats $/ \mathrm{min}$ ). Considering the multicollinearity statistical phenomenon, our regression model was established with the variables of age, height, sex, and $\Delta$ heart rate. The equations were established considering the observation of 1,364 children (group equation). The criteria to choose the best regression model was based on the observation of mean error, error SD, and mean square error. The decision to establish 2 equations, one for boys and one for girls, was made so that it would be easier to interpret the effects of each independent variable for sex and to avoid the possibility of interaction effects for sex and other variables included in the model.
We established 6MWT reference values for boys with the following equation: Distance $=(16.86 \times$ age $)+(1.89 \times \Delta$ heart rate $)-(0.80 \times$ weight $)+(336.91 \times \mathrm{R} 1)+(360.91 \times$ $\mathrm{R} 2)$. For girls the equation is as follows: Distance $=(13.54 \times$ age $)+(1.62 \times \Delta$ heart rate $)-(1.28 \times$ weight $)+$ $(352.33 \times \mathrm{R} 1)+(394.81 \times \mathrm{R} 2)$. If the investigator chooses not to use the variable region of Brazil, just add the value of the 2 coefficients (R1 and R2) and divide by $2 . \mathrm{R} 1$ and $\mathrm{R} 2$ work as dummy variables.

The selected equations were evaluated through comparison of predicted and observed data. The correlation coefficient between the maximum walked distance of the 1,364 children with the distance predicted by the formula was $\mathrm{R}=0.6$ for boys and $\mathrm{R}=0.6$ for girls (Fig. 3).

The established equations were also tested on an independent sample of 132 healthy children 7-12 y old (group test). The equations produced an error of approximately $10 \mathrm{~m}$ for boys and for girls, which is acceptable in clinical practice. The correlation between the predicted and the walked distance showed good results, with $\mathrm{R}=0.5$ for boys and $\mathrm{R}=0.5$ for girls.

\section{Discussion}

This study established reference values for the maximum 6MWD for healthy children in Brazil. The variables that predicted maximum 6MWD were age, weight, Brazilian region, and heart rate variation during the test. In addition, the established equations (one for boys and one for girls) predicted the maximum 6MWD when tested on an independent sample.

A recently published systematic review ${ }^{20}$ analyzed the reference values for the 6MWT in healthy children available worldwide through national studies and found that 
there could be a variation of up to $159 \mathrm{~m}$ from one country to the next. This difference means that if we use an equation to predict the maximum 6MWD that was established in another country, we could be making a significant interpretation mistake. Our study reinforces the need to establish reference values through multicenter representative samples in countries with large territory and cultural diversity, such as the United States of America or Brazil.

This is of great clinical importance if we consider the minimally significant difference already established in several adult populations, such as $32 \mathrm{~m}$ for heart failure, ${ }^{21}$ $25 \mathrm{~m}$ for coronary artery disease, ${ }^{22}$ and $30 \mathrm{~m}$ for COPD. ${ }^{23}$ However, no minimally significant difference is available for children.

Brazilian studies with children and the 6MWT are available in the literature, including one involving sickle-cell anemia $^{24}$ and another involving kidney disease. ${ }^{25}$ These studies showed that the performance in the 6MWT was lower than predicted, but the authors used reference values from other countries. ${ }^{23,24}$ In another Brazilian study involving children with cystic fibrosis, ${ }^{26}$ the authors evaluated the relationship between maximum 6MWD with hospitalization time. The authors used the reference values for the 6MWT in healthy children in Porto Alegre, a city in southern Brazil. However, we cannot extrapolate these results to the rest of the country. Brazil is a country with great climatic, socioeconomic, and cultural differences.

When comparing the mean 6MWD found in our study with the study by Priesnitz et al ${ }^{22}(579.4 \mathrm{~m})$, we identified a discrepancy of $61 \mathrm{~m}$. The difference in our study was the use of an additional variable, Brazilian region, to establish the equation to predict the maximum 6MWD, in light of the variations in our country. The use of this variable makes the equations more precise in predicting the maximum 6MWD. However, our equations can also be used without taking into account the Brazilian region. In this case, it is necessary to add the values of the variables R1 and $\mathrm{R} 2$ and divide by 2 , but in doing so, the equation loses power to predict maximum walking distance.

Our study has some limitations. Our sample size calculation was based on Brazilian regions and not states. Even knowing that this is not the best scenario, our study represents the largest sample available in a Brazilian study. Moreover, our sample was not randomized, and the socioeconomic profiles of the subjects were not evaluated. In addition, the children were separated by chronological age rather than by biological maturity. Although there is some disagreement about the influence of biological maturity on exercise performance, ${ }^{27}$ it is important to highlight this theme. A recent meta-analysis ${ }^{28}$ showed that short-term resistance training was effective in improving strength in boys, and that this improvement was sensitive to level of biological maturity. This difference in strength was attrib- uted to neurological and morphological adaptations mediated by the influence of growth hormones and androgens during puberty. No meta-analysis is available about biological maturation and peak aerobic capacity.

Regarding the number of tests, the recent guideline ${ }^{19}$ suggests performing 2 tests with $1 \mathrm{~h}$ between them in a longitudinal follow-up. Although we understand that the learning effect is real in the 6MWT, we acknowledge the lack of 2 tests is a limitation of our study. ${ }^{19}$

\section{Conclusion}

This study established the reference values for the maximum 6MWD for healthy children in Brazil. In addition, the equations established in this study predicted the maximum walking distance with errors of approximately of $10 \mathrm{~m}$ when tested in an independent sample.

\section{REFERENCES}

1. ATS Committee on Proficiency Standards for Clinical Pulmonary Function Laboratories. ATS statement: guidelines for the six-minute walk test. Am J Respir Crit Care Med 2002;166(1):111-117.

2. Maltais F, Decramer M, Casaburi R, Barreiro E, Burelle Y, Debigaré $\mathrm{R}$, et al. An official American Thoracic Society/European Respiratory Society statement: update on limb muscle dysfunction in chronic obstructive pulmonary disease. Am J Respir Crit Care Med 2014; 189(9):e15-e62.

3. Boxer RS, Kleppinger A, Ahmad A, Annis K, Hager WD, Kenny AM. The 6-minute walk is associated with frailty and predicts mortality in older adults with heart failure. Congest Heart Fail 2010; 16(5):208-213.

4. Nery RM, Martini MR, Vidor CR, Mahmud MI, Zanini M, Loureiro A, Barbisan JN. Changes in functional capacity of patients two years after coronary artery bypass grafting surgery. Rev Bras Cir Cardiovasc 2010;25(2):224-228.

5. Paridon SM, Alpert BS, Boas SR, Cabrera ME, Caldarera LL, Daniels SR, et al. Clinical stress testing in the pediatric age group: a statement from the American Heart Association Council on Cardiovascular Disease in the Young, Committee on Atherosclerosis, Hypertension, and Obesity in Youth. Circulation 2006;113(15):19051920.

6. Rhodes J, Tikkanen AU, Jenkins KJ. Exercise testing and training in children with congenital heart disease. Circulation 2010;122:19571967.

7. Moalla W, Gauthier R, Maingourd Y, Ahmaidi S. Six-minute walking test to assess exercise tolerance and cardiorespiratory responses during training program in children with congenital heart disease. Int J Sports Med 2005;26:756-762.

8. Nixon PA, Joswiak ML, Fricker FJ. A six-minute walk test for assessing exercise tolerance in severely ill children. J Pediatr 1996; 129(3):362-366.

9. Griese M, Busch P, Caroli D, Mertens B, Eismann C, Harari M, et al. Rehabilitation programs for cystic fibrosis: view from a $\mathrm{CF}$ center. Open Respir Med J 2010;7(4):1-8.

10. Andrade LB, Silva DARG, Salgado TLB, Figueroa JN, Lucena-Silva $\mathrm{N}$, Britto MCA. Comparison of six-minute walk test in children with moderate/severe asthma with reference values for healthy children. J Pediatr 2014;90(3):250-257. 


\section{MWD Reference VAlues for BRAZILIAN ChildRen}

11. Li AM, Yin J, Yu CCW, Tsang T, So HK, Wong E, et al. The six-minute walk test in healthy children: reliability and validity. Eur Respir J 2005;25:1057-1060.

12. Lammers AE, Hislop AA, Flynn Y, Haworth SG. The 6-minute walk test: normal values for children of 4-11 years of age. Arch Dis Child 2008;93(6):464-468.

13. Tonklang N, Roymanee S, Sopontammarak S. Developing standard reference data for thai children from a six-minute walk test. J Med Assoc Thai 2011;94(4):470-475.

14. Kanburoglu MK, Ozdemir FM, Ozkan S, Tunaoglu FS. Reference values of the 6-minute walk test in healthy Turkish children and adolescents between 11 and 18 years of age. Respir Care 2014;59(9): 1369-1375.

15. D'silva C, Vaishali K, Venkatesan P. Six-minute walk test-normal values of school children aged 7-12 y in India: a cross-sectional study. Indian J Pediatr 2012;79(5):597-601.

16. Keppler SE, Muir N. Reference values on the 6-minute walk test for children living in the United States. Pediatr Phys Ther 2011;23(1): 32-40.

17. Priesnitz CV, Rodrigues GH, Stumpf CdaS, ViapianaG, Cabral $\mathrm{CP}$, Stein RT, et al. Reference values for the 6-min walk test in healthy children aged 6-12 years. Pediatr Pulmonol 2009;44(12): 1174-1179.

18. Jennen-Steinmetz C, Wellek S. A new approach to sample size calculation for reference interval studies. Stat Med 2005;24(20):31993212.

19. Holland AE, Spruit MA, Troosters T, Puhan MA, Pepin V, Saey D, et al. An official European Respiratory Society/American Thoracic Society technical standard: field walking tests in chronic respiratory disease. Eur Respir J 2014;44(6):1428-1446.

20. Cacau LAP, Santana-Filho VJ, Maynard LG, Gomes Neto M, Fernandes M, Carvalho VO. Six-minute walk test in children and adolescents. Braz J Cardiovasc Surg 2016;31(5):381-388.
21. Shoemaker MJ, Curtis AB, Vangsnes E, Dickinson MG. Clinically meaningful change estimates for the six-minute walk test and daily activity in individuals with chronic heart failure. Cardiopulm Phys Ther J 2013;24(3):21-29.

22. Gremeaux V, Troisgros O, Benaïm S, Hannequin A, Laurent $Y$, Casillas JM, Benaim C. Determining the minimal clinically important difference for the six-minute walk test and the 200-meter fastwalk test during cardiac rehabilitation program in coronary artery disease patients after acute coronary syndrome. Arch Phys Med Rehabil 2011;92(4):611-619.

23. Polkey MI, Spruit MA, Edwards LD, Watkins ML, Pinto-Plata V, Vestbo J, et al. Six-minute-walk test in chronic obstructive pulmonary disease: minimal clinically important difference for death or hospitalization. Am J Respir Crit Care Med 2013;187(4):382386.

24. Hostyn SV, de Carvalho WB, Johnston C, Braga JAP. Evaluation of functional capacity for exercise in children and adolescents with sickle cell disease through the six-minute walk test. J Pediatr 2013; 89(6):588-594.

25. Watanabe FT, Koch VHK, Juliani RCTP, Cunha MT. Six-minute walk test in children and adolescents with renal diseases: tolerance, reproducibility and comparison with healthy subjects. Clinics 2016; 71(1):22-27.

26. Donadio MVF, Heinzmann-Filho JP, Vendrusculo FM, Frasson PXH, Marostica PJC. Six-minute walk test results predict risk of hospitalization for youths with cystic fibrosis: a 5-year follow-up study. J Pediatr 2017;182:204-209.

27. Armstrong N. Top 10 research questions related to youth aerobic fitness. Research Quarterly for Exercise and Sport 2017;88(2):130-148.

28. Moran J, Sandercock GRH, Ramírez-Campillo R, Meylan C, Collison J, Parry DA. A meta-analysis of maturation-related variation in adolescent boy athletes' adaptations to short-term resistance training. J Sports Sci 2017;35(11):1041-1051. 